\title{
Chlorfenapyr Induce Oxidative Phosphorylation Deficiency in Exposed Rat and the Quinoa Effective Role
}

\author{
Reda K. Abdel-Razik ${ }^{1}$, Nadia A. Hamed ${ }^{1}$
}

\begin{abstract}
The present study investigates uncouple and prooxidant effects of chlorfenapyr (CFp) on rat liver and spleen mitochondria respiratory complexes and evaluates the quinoa seeds $(Q)(30 \%$ from the basal diet) effects on CFp exposed rats. Repeated sublethal oral doses of CFp

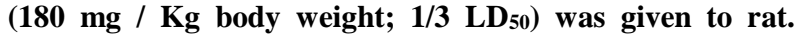
Liver and spleen mitochondria were isolated at the end of the fourth week after dosing. Changes in liver and spleen mitochondrial respiration complexes, and concomitant oxidative stress and antioxidant alterations were examined. Since, CFp provokes a significant reduction in the activity of NADH dehydrogenase (complex I), succinate dehydrogenase (complex II), ubiquinone cytochrome c oxidoreductase (complex III), cytochrome c oxidase (complex IV), superoxide dismutase (SOD), and reduced glutathione (GSH) level. In addition, a significant increase in ATP synthase (complex V) and malondialdehyde (MDA) levels were observed in both liver and spleen mitochondria, indicating clearly an intense peroxidation within mitochondria. So, the results conclude that hepatic and splenic respiratory complexes in rats were severely compromised following CFp exposure. Moreover, $Q$ enhanced diet neutralizes the CFp adverse effect that encourages its use as a mitochondrial enriches source and a protective antioxidant food supplement.
\end{abstract}

Key words: Chlorfenapyr, Electron transport chain, Mitochondria, Oxidative stress, Quinoa.

\section{INTRODUCTION}

In the mammalian body, the liver is the major detoxifying organ and is also involved in xenobiotic metabolism. Although the liver, and spleen work together to activate the defense response to blood-borne pathogens through innate and adaptive immunity, the spleen acts as the center of the blood defense system (Kashimura, 2020). In physiological conditions, mitochondria have significant roles in the metabolism and energy regulation as a source of reactive oxygen species (ROS) that generating approximately $85 \%$ of the total cellular superoxide radical $\left(\mathrm{O}_{2} \bullet\right.$-) (Samarghandian et al., 2016). Mitochondrial impairment can induce oxidative stress and reduce adenosine triphosphate
(ATP) content (Samarghandian et al., 2015). The oxidative attack on the mitochondria is also essential in these events. Impairment of mitochondrial function is the primary mechanism involved in the pathogenesis of neurological disorders (Samarghandian et al., 2016). Mitochondria produce $(\mathrm{O} 2 \cdot-)$, hydrogen peroxide $\left(\mathrm{H}_{2} \mathrm{O}_{2}\right)$, and hydroxyl radical $(\mathrm{OH} \bullet)$ as byproducts of molecular oxygen consumption in the electron transport chain (Barbosa et al., 2020). The accumulated $\mathrm{O}_{2}$ • is eliminated by manganese superoxide dismutase (MnSOD), which generates $\mathrm{H}_{2} \mathrm{O}_{2}$. The mitochondrial glutathione system plays a crucial role in reducing $\mathrm{H}_{2} \mathrm{O}_{2}$ and protects mitochondria against oxidative stress. Various pesticides can cause impaired energy regulation and cell dysfunction, and finally, cell death has been observed in many neurological disorders (De Castro et al., 2011).

Under conditions of mitochondrial dysfunction, ATP deficiency can lead to failure of the $\mathrm{Na}+\mathrm{K}+$ ATPase, and in primary sensory neurons, this may contribute to the ectopic activity characteristic of neuropathic pain (Lim et al., 2015). The oxidative stress of mitochondrial proteins, lipids, and antioxidant enzymes can be seriously harmful.

Lipid peroxidation (LPO) is caused by free radicals that lead to oxidative destruction of polyunsaturated fatty acids, resulting in toxic and reactive aldehyde metabolites such as malondialdehyde (MDA) (Yaman and Ayhanci, 2021). MDA causes mitochondrial dysfunction by enhancing reactive oxygen species (ROS) generation and modulation of mitochondrial proteins (Caldiroli et al., 2020).

Pesticides are rapidly metabolized in the liver by hydrolytic ester cleavage, and oxidative pathways by cytochrome $\mathrm{P} 450$ enzymes produce ROS (He et al., 2020). CFp is a broad-spectrum pyrrole insecticide, which show contact and stomach toxicity (Gunning and Moores, 2002; N'guessan et al., 2007) . It's used to manage veterinary and agricultural pests that have developed resistance to organophosphate, carbamate, and pyrethroid insecticides (Sleem et al., 2019).

DOI: 10.21608/asejaiqjsae.2021.201175

${ }^{1}$ Mammalian Toxicology Department,

Central Agricultural Pesticide Laboratory,

Agricultural Research Center, 21616-El-Sabahia, Baccous,

Alexandria, Egypt

Corresponding author E-mail address:

redarazik216@gmail.com (Reda K. Abdel-Razik).

Received September 20, 2021, Accepted, October 25, 2021. 
According to WHO (Tomlin, 2000), CFp is classified as a slightly hazardous insecticide, however, it was banned in Europe due to its high persistence in the environment (Van Leeuwen et al., 2004), and is still widely used in Egypt (Sleem et al., 2019). CFp; a pyrrole insecticide works by targeting the oxidative pathways in the insect's mitochondria thus disrupting ATP production (Black et al., 1994; guessan et al., 2007).

The aim of this work was to evaluate the mammalian toxicity of CFp by investigating the activity changes of the respiratory complexes of liver and spleen mitochondria of male albino rats after sub-chronic exposure to chlorfenapyr such as (NADH dehydrogenase (complex I), succinate dehydrogenase (complex II), ubiquinone cytochrome c oxidoreductase (complex III), cytochrome c oxidase (complex IV), and $\mathrm{Mg}^{2+}$ ATP (complex V). In addition, oxidative stress biomarkers; MDA, SOD and GSH were studied.

\section{MATERIAL AND METHODS}

\section{Chemicals}

Chlorfenapyr (Corps Top 24\% SC) was obtained from Agrimar Company for Commercial Agencies. Quinoa seeds were purchased from CEDAR, Phoenicia Group Inc. Montreal, H4S 1T2 QC, Canada. All other reagents and chemicals used in this research were obtained from Sigma- Aldrich Chemical Co. (St. Louis, MO, USA).

\section{Animals}

Twenty adult male albino rats, weighing $150-160 \mathrm{~g}$ were obtained from the Faculty of Science; Alexandria University. Rats were allowed to acclimatize for 14 days before the initiation of the experiment under laboratory conditions ( $12 \mathrm{~h}$ light / $12 \mathrm{~h}$ dark, $22-26^{\circ} \mathrm{C}$., $40-70 \%$ humidity). To facilitate measures of food intake, rats were housed conventionally in individual stainless steel hanging wire-mesh cages, with food and tap water provided ad libitum. On arrival, the rats in each experiment were immediately placed in their respective experimental conditions and allowed access to a pre-weighed amount of food so that the first intake measures could be carried out the next day. All procedures involving animals were performed in accordance with Organization for Economic Cooperation and Development, Acute Oral Toxicity Study in Rodents: OECD guideline, 420 (2001).

\section{Experimental design}

The animals were divided into equal four groups (5/each group), and orally treated 5 doses / week over a period of 4 weeks as the following: Group C: Rats were served as control and given commercial basal diet. Group QS: Rats were given QS at 30\% from the basal diet. Group CFp: Rats were given CFp $180 \mathrm{mg} / \mathrm{kg}$ bw which represents $1 / 3 \mathrm{LD}_{50}\left(\right.$ Oral $\mathrm{LD}_{50}$ for Corps Top ( $24 \% \mathrm{SC}$ ) as a commercial chlorfenapyr was $544.3 \mathrm{mg} /$ $\mathrm{kg}$ bw; according to Weil's method (Weil, 1952)).

Group CFp + QS: Rats were given CFp $180 \mathrm{mg} / \mathrm{kg}$ bw plus QS at 30\% from the basal diet. CFp was orally administrated to animals by esophageal intubation. The animal body weights of all groups were recorded weekly. At the end of the experiment (4 weeks), the liver and spleen were quickly removed, weighed individually and the \% of relative organ weight was calculated (organ weight/body weight) X 100 . The liver and spleen were washed with $0.9 \% \mathrm{NaCl}$ and frozen until use.

\section{Isolation of rat liver and spleen mitochondria}

Rat liver and spleen mitochondria were isolated using a slightly modified protocol (Krause et al., 2005). Tissue was homogenized with 10 volumes (w/v) of 250 $\mathrm{mM}$ sucrose, $50 \mathrm{mM}$ Tris-HCL, $5 \mathrm{mM}$ EDTA, and 0.5 $\mathrm{mM}$ phenylmethylsulfonyl fluoride (PMSF), $\mathrm{pH} 7.4$ buffer using a glass Teflon homogenizer. The homogenate was centrifuged at $800 \mathrm{xg}$ for $10 \mathrm{~min}$ at 4 ${ }^{\circ} \mathrm{C}$. Then the supernatant was centrifuged at $8,000 \mathrm{~g}$ for $10 \mathrm{~min}$ at $4{ }^{\circ} \mathrm{C}$, and the pellets were washed twice and suspended in $250 \mathrm{mM}$ sucrose, $0.5 \mathrm{mM}$ PMSF. The isolated mitochondria was frozen as aliquots and stored at $-20{ }^{\circ} \mathrm{C}$.

\section{Determination of protein}

The protein content of mitochondrial preparations was measured by the method of Lowry et al., (1951) using bovine serum albumin as a standard.

\section{Assessment of mitochondrial respiratory complexes}

\section{NADH dehydrogenase (Complex I) activity}

$\mathrm{NADH}$ dehydrogenase activity was measured according to Galante and Hatefi, (1978), which depends on the oxidation of $\mathrm{NADH}$, as follows: Incubate mitochondrial protein $(40 \mu \mathrm{g} / \mathrm{ml})$ in the mixture containing $40 \mathrm{mM}$ phosphate buffer, $\mathrm{pH} 7.4,0.1 \%$ sodium cholate, $1.5 \mathrm{mM}$ potassium cyanide and $1.3 \mathrm{mM}$ potassium ferricyanide, as an electron acceptor for 1 min at $30^{\circ} \mathrm{C}$. The reaction was started by adding 0.14 $\mathrm{mM} \mathrm{NADH}$, and a decrease of absorption was followed spectrophotometrically at $340 \mathrm{~nm}$ for 1-3 minutes. Results expressed as $\mu$ mol NADH oxidized / min / mg protein. Rotenone-sensitivity activity was monitored using $(1 \mu \mathrm{M})$.

\section{Succinate dehydrogenase (Complex II) activity}

Succinate dehydrogenase activity was measured according to the method of King, (1967) . one ml assay mixture containing $0.1 \mathrm{M} \mathrm{pH} 7.4$ phosphate buffer,; EDTA, $0.3 \mathrm{mM}$; sodium succinate, $20 \mathrm{mM}$; 2,6Dichlorophenolindophenol (DCIP), $0.053 \mathrm{mM}$; potassium cyanide, $1 \mathrm{mM}$ and an appropriate amount of enzyme (usually $20 \mu 1$ ) to start the reaction. The activity 
of succinate dehydrogenase is followed by the decrease of the absorbance at $600 \mathrm{~nm}$, readings were taken at intervals of 30 seconds for 2 minutes, and expressed as, $\mu$ moles of succinate oxidized $/ \mathrm{min} / \mathrm{mg}$ protein.

\section{Cytochrome C reductase (Complex III) activity}

The reduction of cytochrome $\mathrm{c}$ was measured spectrophotometrically at $38^{\circ}$ by the increase in optical density at $550 \mathrm{~nm}$ (Green and Ziegler, 1963). The assay system $(1 \mathrm{ml})$ consisted of; $50 \mathrm{mM}$ phosphate buffer $\mathrm{pH}$ 7.4, $0.1 \mathrm{mM}$ EDTA, $1 \mathrm{mg} / \mathrm{ml}$ cytochrome c, $1.6 \mathrm{mM}$ potassium cyanide, $1 \mathrm{mM}$ NADH, $10 \%$ sodium cholate, and 10 or $20 \mu \mathrm{l}$ enzyme last addition. Readings were taken every 15 seconds for 2 minutes. The specific activity was expressed as $\mu$ moles of reduced cytochrome $\mathrm{c} / \mathrm{min} / \mathrm{mg}$ protein. The extinction coefficient of reduced cytochrome c at $550 \mathrm{~nm}$ was $18.5 \times 10^{6} \mathrm{~cm}^{2} /$ mole.

\section{Cytochrome c oxidase (Complex IV) activity}

The oxidation of cytochrome $\mathrm{c}$ was colorimetrically measured by the decrease in absorbance at $550 \mathrm{~nm}$ Green and Ziegler, (1963). The assay system (1ml) containing; $50 \mathrm{mM}$ phosphate buffer $\mathrm{pH} 7.4,0.1 \mathrm{mM}$ EDTA, $1 \mathrm{mg} / \mathrm{ml}$ cytochrome c, $10 \%$ sodium cholate, and $20 \mu \mathrm{l}$ enzyme as a last addition. Readings were taken every 15 seconds for 2 minutes. The enzyme activity was expressed as moles of oxidized cytochrome c /min $/ \mathrm{mg}$ protein. The extinction coefficients of oxidized cytochrome c at $550 \mathrm{~nm}$, was $19.6 \mathrm{mM}^{-1} \mathrm{~cm}^{-1}$.

\section{5. $\mathrm{Mg}^{2+}$ ATPase (Complex V) activity}

The basic idea of this method is to measure the amount of inorganic phosphate produced from the hydrolytic reaction of ATP by the ATPase. In this method, mitochondria $(1 \mathrm{mg}$ protein/ $/ \mathrm{ml})$ were added to a medium containing, $20 \mathrm{mM}$ Tris- $\mathrm{HCl}, \mathrm{pH} 7.6,5 \mathrm{mM}$ $\mathrm{MgCl}_{2}$ and $5 \mathrm{mM}$ ATP. Then the mixture was incubated for $5 \mathrm{~min}$. at $37^{\circ} \mathrm{C}$ in a shaking water bath. The reaction was stopped by the addition of 5\% trichloroacetic acid (TCA), and then inorganic phosphate (Pi) was determined calorimetrically at $740 \mathrm{~nm}$ (Taussky and Shorr, 1953). The activity of ATPase was expressed as $\mu$ mole $\mathrm{Pi} / \mathrm{mg}$ protein/min.

\section{Assessment of mitochondrial oxidative stress biomarkers}

\section{a) Superoxide Dismutase (SOD) activity}

SOD as an enzymatic antioxidant was measured spectrophotometrically at $25{ }^{\circ} \mathrm{C}$ by the method of Marklund and Marklund (1974) with some modifications. The assay medium in a total volume of $1.0 \mathrm{ml}$ contains $50 \mathrm{mM}$ Tris $-\mathrm{HCl}, \mathrm{pH} 8.0$, and 0.24 $\mathrm{mM}$ pyrogallol. The Autoxidation of pyrogallol was monitored at $420 \mathrm{~nm}$ for $3 \mathrm{~min}$ in the absence and presence of enzyme. At least three concentrations of the enzyme which produced between 30 to $60 \%$ inhibition of pyrogallol autoxidation were used. One unit of enzyme activity is defined as the amount that produced $50 \%$ inhibition of pyrogallol autoxidation under the standard assay conditions. Mitochondrial SOD activities were expressed as Units/ mg protein.

\section{b) Reduced Glutathione (GSH) content}

GSH level was determined as described by Ellman, (1959). The mitochondrial suspension in $0.1 \mathrm{M}$ phosphate buffer, $\mathrm{pH} 7.4$ was added to an equal volume of $10 \%$ TCA. The mixture was allowed to stand for 10 min in ice bath prior to centrifugation at $4000 \mathrm{xg}$ for 10 min. $2.5 \mathrm{ml}$ of Ellman's reagent (39.6 mg of DTNB and $15 \mathrm{mg} \mathrm{NaHCO}$ in $10 \mathrm{ml} 0.1 \mathrm{M}$ phosphate buffer, $\mathrm{pH}$ 7.0) was added to $0.5 \mathrm{ml}$ of the supernatant, shaked and then measured at $412 \mathrm{~nm}$ against blank. GSH concentration was estimated and obtained from the GSH standard curve as $\mu$ mole/g tissue.

\section{c) Lipid peroxidation (LPO) level}

Malondialdehyde has been identified as the product of lipid peroxidation that reacts with thiobarbituric acid (TBA) to give a pink-colored complex absorbing at 535 $\mathrm{nm}$ Buege and Aust, (1978). Briefly, $0.5 \mathrm{ml}$ of mitochondrial suspension was reacted with $2 \mathrm{ml}$ of TBA reagent containing $0.375 \%$ TBA, $15 \%$ TCA, and 0.25 $\mathrm{N}$ HCL. Samples were boiled for $15 \mathrm{~min}$, cooled and centrifuged. The yields supernatants were measured at $535 \mathrm{~nm}$. The LPO level was calculated using the molar extinction coefficient $=155 \mathrm{mM}^{-1} \mathrm{~cm}^{-1}$, and the results were expressed as nmol MDA/mg protein.

\section{Statistical analysis}

All results were expressed as mean \pm standard error (SE). The data were analyzed using a one-way analysis of variance (ANOVA) followed by the StudentNewman-Keuls test. The criterion for statistical significance was set at $p \leq 0.05$. These tests were performed using the computer software CoStat program, version 6.400 (CoHort Software: Tucson, 1998-2008).

\section{RESULTS AND DISCUSSION}

\section{RESULTS}

\section{Body and Relative organ weights}

No mortality or clinical signs of toxicity was founded in any treated animal. The physiological status of control and treated animals was observed as the change in body and organ weights. Data in Table (1) illustrated a significant $(p \leq 0.05)$ decrease in the body weight of CFp treated rats by $19.1 \%$ while, the QSenriched diet enhanced body weight loss by $11.2 \%$ compared to control. The relative liver and spleen weights were increased by $48.7 \%$ and $48.8 \%$ respectively related to control. While, the QS-enhanced diet alleviated the effect of CFp exposed rats to $21.21 \%$ 
and $4.65 \%$ for the liver and spleen, respectively compared to the control (Table 1).

\section{Biochemical effects of chlorfenapyr exposure}

The effects of orally dosed CFp (180 mg/kg bw; 1/3 $\mathrm{LD}_{50}$ ) on the mitochondrial respiratory chain complexes, the enzymatic and non-enzymatic antioxidant defense, and, the protective effects of QS against CFp in the liver and spleen of male rat were presented in Figures 1 and 2 and Tables 2and3.

\section{NADH dehydrogenase (complex I) activity}

Current data showed that the CFp dosing significantly $(p \leq 0.05)$ decreased complex I activity of liver and spleen mitochondria by $36.4 \%$ and $33.2 \%$, respectively, while supplementation with QS modified the CPF toxic effect to $22.4 \%$ and $8.5 \%$ for liver and spleen, respectively related to control (Fig. 1 and 2). As noted, the attenuation of the toxic effect by QS enhanced diet was more promising in the spleen than in the liver.

\section{Succinate dehydrogenase (complex II) activity}

Consistently, the CFp intoxicated animals revealed a significant $(p \leq 0.05)$ decline in complex II activity of liver and spleen mitochondria by $38.6 \%$ and $26.4 \%$, respectively, while feeding on QS enhanced diet modulates the CFp effect to $3.1 \%$ and $17.1 \%$ for liver and spleen mitochondria, respectively compared to control (Fig.1 and2).
Ubiquinone III) activity

cytochrome c oxidoreductase (complex

The complex III activities of liver and spleen mitochondria were significantly $(p \leq 0.05)$ decreased by $40.1 \%$ and $45 \%$, respectively in rats given CFp. However, concomitantly supplementation by QS improved diet markedly mitigated the CFp effect to be $6.5 \%$ and $15 \%$ for liver and spleen mitochondria, respectively related to control (Fig. 1 and 2).

Cytochrome c oxidase (complex IV) activity

Obtained results in Fig. 1 and 2 revealed that the complex IV activity of liver and spleen mitochondria were significantly $(p \leq 0.05)$ inhibited by $54 \%$ and 36.4 $\%$, respectively, due to $\mathrm{CFp}$ treatment, however, concurrently QS enriched diet supplementation noticeably alleviated the CFp harm effect to $17.6 \%$ and $27.3 \%$ for liver and spleen mitochondria, respectively paralleled to control (Fig. 1 and 2).

\section{$\mathrm{Mg}^{2+}$ ATPase (Complex V) activity}

Contrary, a significant increase in the mitochondrial ATPase activity by $60.6 \%$ and $35.3 \%$ for rat liver and spleen, respectively were observed after CFp administration. While the CFp administration concomitantly with QS enhanced diet neutralizes the CFp stimulated effect to $35.7 \%$ and $17.6 \%$ for liver and spleen mitochondria, respectively regarded to control (Fig. 1 and 2).

Table 1. Relative liver and spleen weights percentage and body weight of male rats after 28 days of treatment with chlorfenapyre (180 $\mathrm{mg} / \mathrm{kg}$ bw), quinoa seed (30\% of basal diet) and their combination

\begin{tabular}{lccc}
\multicolumn{1}{c}{ Animal Group } & $\begin{array}{c}\text { Relative liver } \\
\text { weight }(\%)\end{array}$ & $\begin{array}{c}\text { Relative spleen } \\
\text { weight }(\%)\end{array}$ & $\begin{array}{c}\text { Gained body weight } \\
(\mathbf{g m})\end{array}$ \\
\hline Control & $3.63 \pm 0.08^{\mathrm{c}}$ & $0.43 \pm 0.01^{\mathrm{b}}$ & $101.7 \pm 1.2^{\mathrm{a}}$ \\
Quinoa seed & $3.5 \pm 0.21^{\mathrm{c}}$ & $0.49 \pm 0.03^{\mathrm{b}}$ & $95.0 \pm 1.1^{\mathrm{b}}$ \\
Chlorfenapyr & $5.4 \pm 0.33^{\mathrm{a}}$ & $0.64 \pm 0.04^{\mathrm{a}}$ & $82.3 \pm 1.4^{\mathrm{d}}$ \\
$\begin{array}{l}\text { Chlorfenapyr plus } \\
\text { Quinoa seed }\end{array}$ & $4.4 \pm 0.1^{\mathrm{b}}$ & $0.45 \pm 0.01^{\mathrm{b}}$ & $90.3 \pm 0.8^{\mathrm{c}}$ \\
\hline
\end{tabular}

Values are expressed as means (Five rats) \pm standard error (SE).

$*$ Values in a column with the same letters do not statistically differ at $p \leq 0.05$. 

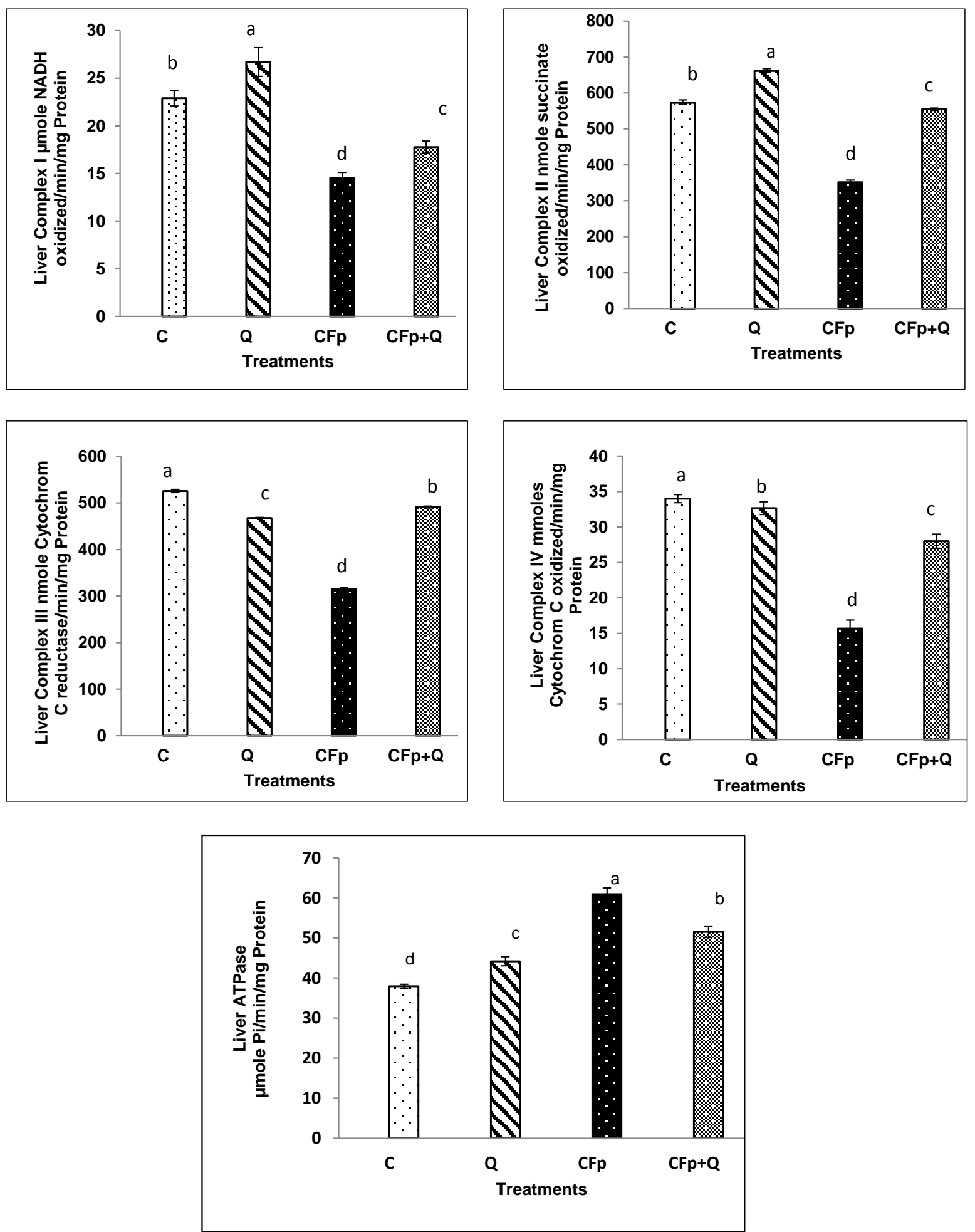

Fig.1. Effects of chlorfenapyr (CFp), quinoa seeds (Q) and their combination $(C F p+Q)$ on the mitochondrial respiratory complexes in rat liver

a,b,c,d different letters are significantly different at $p \leq 0.05$ 

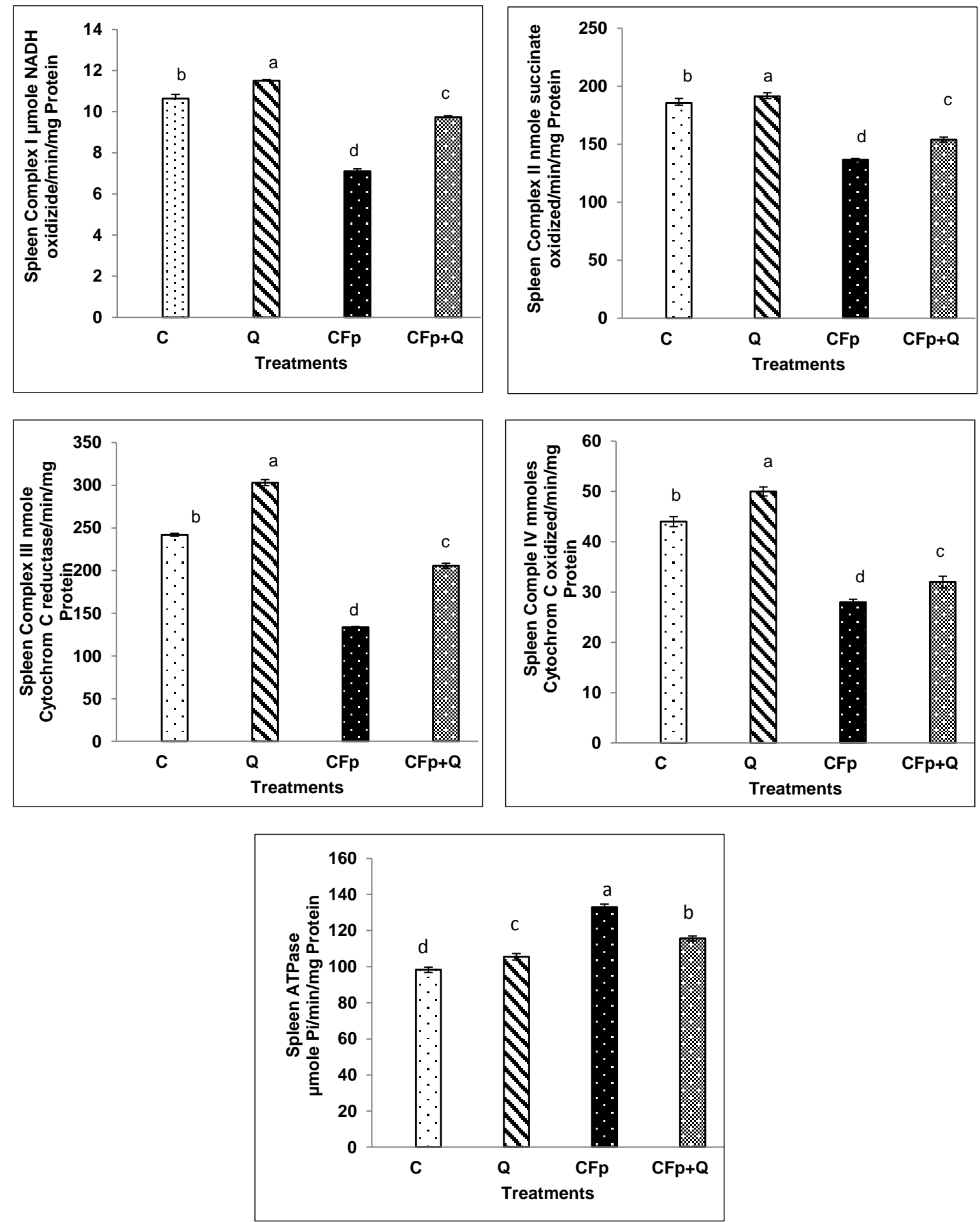

Fig.2. Effects of chlorfenapyr (CFp), quinoa seeds (Q) and their combination $(C F p+Q)$ on the mitochondrial respiratory complexes in rat spleen

a,b,c,d different letters are significantly different at $p \leq 0.05$ 


\section{Superoxide Dismutase (SOD) activity}

The current results in Table (2) showed that SOD activity of liver mitochondria from CFp treated rats was significantly inhibited by $27 \%$ however; the QS supplemented diet concomitantly with CFp treatment reduced the damaging effect of CFp to $19.2 \%$. In addition SOD activity of spleen mitochondria was significantly decreased by $32.1 \%$ while the QS supplemented diet fed concomitantly with CFp administration attenuated the adverse effect of CFp to $19.6 \%$ compared to control (Table 3).

\section{Reduced GSH content}

The obtained results showed that CFp treatment reduced the mitochondrial GSH level in the liver by $31.2 \%$, but the QS complemented diet provided concomitantly with CFp administration, mitigated the negative effect of CFp to $16.5 \%$ (Table 2). Whereas the mitochondrial GSH level of CFp in vivo exposed spleen was declined by $29.8 \%$. However, when a QS supplemented diet was used in conjunction with CFp treatment, the risky effect of CFp was mitigated to $18.8 \%$ related to the control group (Table 3 ).

\section{Lipid peroxidation (LPO) level}

Our data showed a significant elevation in liver mitochondria MDA levels due to CFp exposure to be $23 \%$, indicating a loss of structural and functional integrity of the mitochondrial membrane. While QS supplemented diet concomitantly supplied with oral administration of CFp changed the CFp adverse effect to be $3.8 \%$ compared to control. In addition, the spleen mitochondria were more affected by CFp treatment than the liver, as the MDA level was raised by $92.6 \%$ (Table 2). Whereas, QS enhanced diet given concomitantly with CFp administration attenuated the adverse effect of CFp to $50.5 \%$ compared to control (Table 3 ).

Table 2. Liver mitochondrial oxidative stress biomarkers of male albino rats orally administrated with chlorfenapyr (180 mg/kg bw), quinoa seed (30\% of basal diet) and their combination for 28 days (5 doses/week)

\begin{tabular}{lccc}
\hline \multicolumn{1}{c}{ Animal Group } & $\begin{array}{c}\text { Specific Activity of } \\
\text { SOD (U/mg protein) }\end{array}$ & $\begin{array}{c}\text { Content of GSH } \\
\text { (nmole gluttathion/mg } \\
\text { protein) }\end{array}$ & $\begin{array}{c}\text { Content of MDA } \\
\text { (nmole/mg protein) }\end{array}$ \\
\hline Control & $27.78 \pm 1.3^{\mathrm{a}}$ & $247 \pm 1.6^{\mathrm{b}}$ & $76.5 \pm 0.8^{\mathrm{b}}$ \\
Quinoa seed & $28.18 \pm 1.6^{\mathrm{a}}$ & $250 \pm 1.2^{\mathrm{a}}$ & $70.1 \pm 1.6^{\mathrm{c}}$ \\
Chlorfenapyr & $20.27 \pm 0.9^{\mathrm{b}}$ & $170.3 \pm 4.0^{\mathrm{d}}$ & $94.2 \pm 1.3^{\mathrm{a}}$ \\
Chlorfenapyr plus & $22.43 \pm 0.9^{\mathrm{b}}$ & $206.3 \pm 2.0^{\mathrm{c}}$ & $79.4 \pm 1.0^{\mathrm{b}}$ \\
Quinoa seed & & & \\
\hline
\end{tabular}

Values are expressed as means (Five rats) \pm standard error (SE)

$*$ Values in a column with the same letters do not statistically differ at $\mathrm{p} \leq 0.05$.

Table 3. Spleen mitochondrial oxidative stress biomarkers of male albino rats orally administrated with chlorfenapyr $(180 \mathrm{mg} / \mathrm{kg} \mathrm{bw})$, quinoa seed $(30 \%$ of basal diet) and their combination for 28 days $(5$ doses/week)

\begin{tabular}{lccc}
\hline \multicolumn{1}{c}{ Animal Group } & $\begin{array}{c}\text { Specific Activity of } \\
\text { SOD(U/mg protein) }\end{array}$ & $\begin{array}{c}\text { Content of GSH } \\
\text { (nmole gluttathion/mg } \\
\text { protein) }\end{array}$ & $\begin{array}{c}\text { Content of MDA } \\
\text { (nmole/mg protein) }\end{array}$ \\
\hline Control & $19.17 \pm 0.4^{\mathrm{b}}$ & $240.70 \pm 1.2^{\mathrm{b}}$ & $22.93 \pm 1.6^{\mathrm{c}}$ \\
Quinoa seed & $20.63 \pm 0.8^{\mathrm{a}}$ & $249.00 \pm 1.8^{\mathrm{a}}$ & $19.63 \pm 0.6^{\mathrm{d}}$ \\
$\begin{array}{l}\text { Chlorfenapyr } \\
\text { Chlorfenapyr } \\
\text { Quinoa seed }\end{array}$ & $13.00 \pm 0.6^{\mathrm{c}}$ & $169.00 \pm 1.5^{\mathrm{d}}$ & $44.18 \pm 0.9^{\mathrm{a}}$ \\
\hline
\end{tabular}

Values are expressed as means (Five rats) \pm standard error (SE)

$*$ Values in a column with the same letters do not statistically differ at $\mathrm{p} \leq 0.05$. 


\section{Discussion}

\section{Body and relative organ weights}

Exposure to pesticides is associated with the structural damage to organs and tissues along with pathological and inflammatory changes resulting in altered morphology of affected organs and caused severe acute and chronic poisoning (Arfat et al., 2014; El-Gendy et al., 2019). The present study revealed, a significant decrease in the body weight of CFP treated rats which may be attributed to a reduced food intake (anorexia or food avoidance), poor food tastiness or increased degradation of lipids and protein as a result of CFP treatment El-Gendy et al., (2019). Hepatosplenomegaly is an enlarged liver and spleen caused by hepatic disorders (Costa, 2008). As regards the change of organ weight in treating animals was in accordance with those obtained by El-Gendy et al., (2019) who observed a reduction of the body weight and an increase in the relative organs weight of mice or rats exposed to ethoprophos and chlorfenapyr, respectively. Liver enlargement could be induced as a result of; 1) the maintenance of the liver normal functional capacity (Robinson and Yarbrough, 1978), 2) accumulation of fat, mainly triglyceride (Laothong, 2016), a result of an imbalance between the rate of synthesis and the rate of release of triglyceride by the parenchymal cells into the systemic circulation, or 3) the increased demands for the detoxification of toxic compounds, Kadota et al., (1976). In contrast; Bhatnagar and Jain (1986) stated that the increase in liver weight is not necessarily considered toxic lesions since this effect is observed in a large number of compounds.

\section{Biochemical findings}

The effects of orally dosed CFp (180 mg/kg bw,; 1/3 $\mathrm{LD}_{50}$ ) on the mitochondrial respiratory chain complexes, lipid peroxidation, the enzymatic and non-enzymatic antioxidant, defense, and, the protective effects of QS against CFp in liver and spleen of male rat were brief in Figs. 1-2 and table 2-3.

Mitochondria play an important role in creating cellular bioenergetics that produces NADH and ATP molecules via oxidative phosphorylation. These functions are linked to neurodevelopment, connections, tissue differentiation, and plasticity (Bergman and BenShachar, 2016). Mitochondrial dysfunction is a fundamental pathogenic mechanism that leads to several significant toxicities in mammals, especially those associated with the liver and spleen (Zanoli et al., 2012). Numerous studies have revealed that mitochondrial dysfunction is a significant mechanism of drug-induced toxicity, as well as the primary mechanism in several disorders and a prominent toxicological target (Bergman and Ben-Shachar, 2016). In our results, CFp caused mitochondrial dysfunction in rat's liver, which was confirmed by inhibiting the mitochondrial NADH dehydrogenase. This finding may depend on the configurationally structure of this enzymatic complex, which is made up of at least 40 different polypeptides firmly embedded in the inner mitochondrial membrane (Küffner et al., 1998). The present findings are consistent with the data of Agrawal et al., (2015) who observed that cypermethrin alters the mitochondrial proteome, reduces the membrane potential, decreases the mitochondrial complex I activity, and increases apoptosis in rat's neurons. In agreement lambda cyhalothrin significantly reduce the NADH dehydrogenase activity in hepatic mitochondria of treated rats ( Hamed, (2017). Also, (Guven et al., 2018) reviewed that permethrin and cyhalothrin caused the inhibition of complex $I$ in isolated rat liver mitochondria which may be related to ROS formation. Indeed, the lack of NADH oxidation strongly reduces NAD+ levels, thus impeding the activity of the different NAD+-dependent dehydrogenases of the $\beta$-oxidation and TCA cycle pathways (Massart et al., 2013). Impairment of the TCA cycle can lead to hyperlactatemia and lactic acidosis because the conversion of metabolized pyruvate to lactate by lactate dehydrogenase is favored by NADH accumulation (Margolis et al., 2014).

Biochemical and immunohistochemical analyses have demonstrated that mutations in complex II-related genes often result in the reduction or loss of a functional enzyme complex, which may in turn lead to either the accumulation of succinate King et al., (2006) or the generation of reactive oxygen species (ROS), due to frustrating electron transport (Ishii et al., 2005; Slane et $a l .$, 2006). Present data showed a decrease in complex II activity of liver and spleen mitochondria as a result of toxic effects of the repeated sublethal dose of CFp. These data are consistent with previous researches that found other pesticides inhibited the activity of complexes I and II in the cortex, cerebellum, and brain stem of acutely monocrotophos-and dichlorvos-treated animals. This inhibition was also seen in rats exposed to dichlorvos and parathion in their liver and brain mitochondria (Karami-Mohajeri and Abdollahi, 2013). In addition, suppression of succinic dehydrogenase activity, which is involved in TCA and complex II, was measured in the rat brain following acute and subacute beta-cyfluthrin exposure (Guven et al., 2018) .

Complex III is a key site of reactive oxygen species (ROS) generation within mitochondria. A dysfunction of its catalytic domain in iron-sulfur 
protein blocks electron transport to cytochrome $c_{1}$ and subsequently decreases complex III activity in ischemiadamaged mitochondria (Lesnefsky, 2001). The obtained result revealed a significant reduction in liver and spleen mitochondria complex III activity. In line with KaramiMohajeri and Abdollahi (2013) who reviewed that mevinphos acute exposure resulted in depletion of NADH cytochrome C reductase (Complexes I and III), and succinate cytochrome $\mathrm{C}$ reductase (Complexes II and III) in pheochromocytoma cell lines. In contrast, Lee et al. (2021) postulated that two chlorinated hydrocarbons compounds; chlordane and $\beta$ hexachlorocyclohexane $(\beta-\mathrm{HCH})$, were associated with increased the specific activity of mitochondrial complexes I and III of exposed zebrafish embryos.

The complex IV is the last electron acceptor of the respiratory chain, involved in the reduction of $\mathrm{O}_{2}$ to $\mathrm{H}_{2} \mathrm{O}$ (Castresana et al., 1994). Our data exhibited a significant inhibition of complex IV activity in liver and spleen mitochondria, which in agreement with other studies of acutely monocrotophos-and dichlorvostreated rats, that shown a suppression of complexes I, II, and IV activity in the cortex, cerebellum, and brain stem causes organophosphate-induced delayed neuropathy (Masoud et al., 2009). Similar results were obtained by Delgado et al. (2006) who concluded that malathion causes oxidative stress which could be due to inactivation of mitochondrial respiratory complexes (II and IV) in central nervous system (CNS) of intoxicated rats.

The enzyme ATP synthase (complex V) is not only responsible for the synthesis of ATP from ADP and inorganic phosphate (Pi), it is also capable of a reversible reaction and can hydrolyze ATP. It's a multicomponent structure that spans the inner membrane of mitochondria, the cell's energy generators ( Mühleip et al., 2019). In the present study it was found that CFp intoxication stimulated the complex $\mathrm{V}$ activity in rat liver and spleen. We can conclude that chlorfenapyr poisoning increased complex $\mathrm{V}$ activity by altering mitochondrial membrane permeability and disrupting calcium homeostasis. These results were in agreement with (Delgado-Coello et al., 2006) who postulated that elevated cytoplasmic calcium activates a variety of enzymes with membrane damaging effects and ATPases are among the major enzymes that are involved in calcium activation. In addition, Abdel-Mobdy et al. (2019) found that technical and formulated dimethoate stimulated the activities of the respiratory system (Cytochrome-c-oxidase and succinate-cytochrome-creductase in brain, liver and kidneys tissues of male albino rats. In contrast to previous findings, Zanoli et al. (2012) found that, abamectin has a direct effect on FoF1-ATPase (complex V) and behaves similarly to oligomycin,; a complex V specific inhibitor. In addition,
Abdel-Razik, ( 2019) found that imidacloprid-treated mice had significantly lower brain mitochondrial ATPase activity. Furthermore, the activity of adenosine triphosphatase (complex V) in the brain mitochondria of abamectin-exposed rats was shown to be significantly reduced (Abdel-Razik, and Hamed, 2015). In addition, lambda cyhalothrin intoxication suppressed complex I and $\mathrm{V}$ activities in rabbit liver in vitro Hamed, (2017) .

Antioxidant enzymes are proteins that catalyze the conversion of reactive oxygen species (ROS) and their metabolites into nontoxic, stable compounds. As a result, it's the most significant barrier against oxidative stress-induced cellular damage. Antioxidant defenses mainly consist of enzymatic as SOD and non-enzymatic as glutathione (Thowfeik, 2016). The current results showed that SOD activity of liver and spleen mitochondria was significantly inhibited. The decreased SOD activity in CFp intoxicated rat may be owed to the consumption of this enzyme in converted $\mathrm{O}^{2-}$ to $\mathrm{H}_{2} \mathrm{O}_{2}$. Wheeler et al., (2001) observed that mitochondrial SOD activity had lowered by half, resulting in a functional decrease in oxidative phosphorylation, an increase in oxidative stress, and an increase in the rate of apoptosis. According to the findings, Mn SOD plays a crucial role in the redox state of mitochondria in cells and tissues ( Buettner, (2011). These results are in line with Ranjbar et al., (2010); Wani et al., (2011) who investigated the decrease of mitochondrial function in the rat brain after chronic exposure to malathion and dichlorvos. They further claimed that malathion and dichlorvos cause mitochondrial protein oxidation and disruption of $\mathrm{Mn}$ SOD (mitochondrial SOD) activity, resulting in mitochondrial DNA oxidation and brain damage.

Mitochondrial GSH plays a key role in order to avoid the excessive accumulation of hydrogen peroxide and subsequent oxidative stress (Marí et al., 2013). It is the primary non-protein thiol in cells, with the redoxactive thiol of its cysteine moiety serving as a cofactor for a variety of antioxidant and detoxifying enzymes. GSH is synthesized exclusively in the cytosol from its constituent amino acids, yet it is dispersed throughout the body, including mitochondria, where its matrix concentration equals that of the cytosol. This property and its negative charge at physiological $\mathrm{pH}$, suggests the existence of specific carriers that transport GSH from the cytosol to the mitochondrial matrix, where it is involved in the detoxification of lipid hydroperoxides and electrophiles as well as the defense against respiration-induced ROS.

The current research revealed a significant reduction in liver and spleen GSH content which might be due to either GSH synthesis suppression or increased GSH consumption for toxicant induced free radicals 
detoxification. The decrease in mitochondrial GSH suggests that $\mathrm{CFp}$ oral administration might lead to excessive free radicals production. These free radicals might be attacking the thiol group of cysteine residues and polyunsaturated fatty acids of biological membranes (Raina et al., 2009). These findings run parallel with that previously reported by Sharma et al., (2014) who recorded significant rise in lipid peroxidation and debility in glutathione contents after administration of cypermethrin (at the dose of $3.83 \mathrm{mg} / \mathrm{kg}$ bw for 7 days) in Wister rat brain. Furthermore, Abbassy et al., (2014) observed a significant reduction in GSH level after dosing rats with $2.6 \mathrm{mg} / \mathrm{kg}$ bw of lambda cyhalothrin for 6 weeks (3doses/week). Likewise, chlordane and $\beta$ hexachlorocyclohexane $(-\mathrm{HCH})$ were linked to lower mitochondrial GSH levels in exposed zebrafish embryos, according to Lee et al. (2021) study. Reduced GSH levels in mitochondria lead to an increase in $\mathrm{H}_{2} \mathrm{O}_{2}$ production, which can promote lipid peroxidation, cell membrane damage, and tissue damage (Martín et al., 2000; Şener et al., 2005).

The LPO intensity is one known mechanism of mitochondrial failure in many diseases (Negre-Salvayre et al., 2010). The stimulation of LPO in mitochondrial membranes, combined with oxidative stress, changes their permeability, decreases membrane potential and uncoupled oxidative phosphorylation (Batandier et al., 2004). Our data showed a significant elevation in liver and spleen mitochondria MDA levels due to CFP exposure. Similar results were obtained by Masoud $e t$ al., (2009) who found that after sub-acute exposure to monocrotophos or dichlorvos, there was an increase in MDA levels in mitochondria or cytosol as a result of ROS overproduction. Chlorpyrifos also produced mitochondrial oxidative damage by increasing MDA levels inside them (Xu et al., 2017). Previous research has found that lowering GST levels causes an increase in LPO (Dhouib et al., 2014). The present results are consistent with those of Gultekin et al. (2001), who linked higher LPO levels to pesticide-induced ROS production and SOD inhibition. Also, Tukhtaev et al. (2013) observed that chronic low-dose fipronil exposure elevated LPO in the livers of pregnant rats and their offspring. Furthermore, cypermethrin and methyl parathion significantly increased MDA levels in the hepatic and renal tissues of rats (Gomaa et al., 2011).

In the present study, the organ hypertrophy impact of CFP-exposed rats was mitigated by quinoa seedenhanced diet, and that may be associated to the quinoa hypolipidemic ability. Two studies showed that polysaccharide fractions purified from quinoa exhibited antioxidant and immunomodulatory activities, evidenced by significant radical scavenging activity and anti-inflammatory effect (Yao et al., 2014; Hu et al., 2017). Another research found that a purified quinoa polysaccharide, SQWP-2, inhibited adipocyte differentiation, so it might be useful as an antiobesity agent (Teng et al., 2020).

In mitochondria, docosahexaenoic acid (DHA) helps reduce oxidative stress by regulating antioxidant signaling pathways (Oppedisano et al., 2020). Six to eight percent of the total fat content of quinoa is $\alpha$ linoenic acid, an essential precursor of DHA (Gómez et $a l ., 2021)$. Multiple assays have proven that the antioxidant ability of the active ingredients in quinoa is retained. The results of 2,2-diphenyl-1-picrylhydrazyl (DPPH), 2,2'-azino-bis(3-ethylbenzothiazoline-6sulfonic acid (ABTS+), oxygen radical absorbance capacity (ORAC), lipoxy genase/ 4-nitroso-N,Ndimethylaniline (LOX/RNO), Trolox equivalent antioxidant capacity (TEAC), cellular antioxidant activity (CAA), ferric reducing sntioxidant power (FRAP), (NO•), $\mathrm{NO}$ radical and $\mathrm{H}_{2} \mathrm{O}_{2}$ scavenging assays all indicate that quinoa presents high antioxidant activity (Ayyash et al., 2018; Balakrishnan and Schneider, 2020; Mufari et al., 2021).

Animal experiments have shown that the consumption of quinoa increases the activity of antioxidant enzymes, including SOD, glutathione peroxidase (GPx), and catalase (CAT); as well as affected antioxidant- biomarker that reduces LPO, as evidenced by a decrease of MDA and an increase GSH levels (Ali, 2019; Mohamed et al., 2019; Ahmed et al., 2020; Al-Qabba et al., 2020; Abdel-Wahhab et al., 2021), this is consistent with our results.

Quinoa's antioxidant capacity may owe to the presence of phenolic components, such as flavonoids (Ahmed et al., 2020; Paśko et al., 2009). Balakrishnan and Schneider, (2020) found that following in vitro digestion, seven out of eleven flavonoids remained intact. It means that digestion will have no effect on the function of these flavonoids, which is in line with Chirinos et al. (2020) finding's. Balakrishnan and Schneider, (2020) also observed that gastrointestinal digestion of quinoa flavonoids resulted in a twofold increase in antioxidant capacity, implying that direct quinoa eating may be sufficient to provide a good antioxidant impact.

\section{CONCLUSIONS}

The current study found that sublethal oral administration of chlorfenapyr at $1 / 3 \mathrm{LD}_{50}$ for 28 days, caused cytotoxic changes in the hepatic and splenic mitochondrial respiratory complexes, enzymatic and non-enzymatic antioxidants, thereby weakening the mitochondrial ability of the liver and spleen to manage the CFp oxidative stress. This suggests an overall perturbation of the electron transfer pattern causes mitochondrial dysfunction, abnormalities in 
metabolism, and immunity innate in rats. On the other hand, the sufficient dietary intake of QS riches the mitochondria and may provide significant protection against the CFp negative impact.

\section{REFERENCES}

A Hamed, N. 2017. Protective effect of quercetin against oxidative stress and mitochondrial bioenergetic deficiency caused by lambda-cyhalothrin. Alexandria Sci. Exchange J. 38(January-March). 82-88.

Abbassy, M. A., M. A.Marzouk, S. A.Mansour, H. A.Shaldam and A.Mossa. 2014. Impact of oxidative stress and lipid peroxidation induced by lambdacyhalothrin on p450 in male rats: the ameliorating effect of zinc. J. Environ. Anal. Toxicol. 4(4):1-5.

Abdel-Mobdy, A. E., Y. E.Abdel-Mobdy and A. A.Nassrallah. 2019. Curative Effects of Camel Milk on the Dimethoate Harmful In Energy and Cytochrome-C System in Treated Rats. Egyptian Academic J. of Biological Sciences, B. Zoology. 11(2):19-30

Abdel-Razik, R. K. 2019. The Protective Effect of Nigella sativa Oil on Neurodisorder and Oxidative Stress Driven by Imidacloprid in Mice Mitochondria. Egyptian Scientific J.l of Pesticides. 5:22-31.

Abdel-Razik, R. K. and N. A. Hamed. 2015. Deleterious effect of abamectin on rat brain mitochondria. Alexandria Sci. Exchange J. 36(4): 423-428.

Abdel-Wahhab, K. G., F. A. Mannaa, M.Ashry, D. M.Khaled, L. K.Hassan and H. F.Gomaa. 2021. Chenopodium quinoa ethanolic extract ameliorates cyclophosphamide ${ }^{\circledR}$-induced hepatotoxicity in male rats. Comparative Clinical Pathology. 30(2):267-276.

Agrawal, S., A.Singh, P. Tripathi, M.Mishra, P. K.Singh and M. P.Singh. 2015. Cypermethrin-induced nigrostriatal dopaminergic neurodegeneration alters the mitochondrial function: a proteomics study. Molecular neurobiology. 51(2): 448-465

Ahmed, S. A., A.El-Rahman, I.Ghada, A.Behairy and R. R.Beheiry. 2020. Influence of Feeding Quinoa (Chenopodium quinoa) Seeds and Prickly Pear Fruit (Opuntia ficus indica) Peel on the Immune Response and Resistance to Aeromonas sobria Infection in Nile Tilapia (Oreochromis niloticus). Animals. 10(12):2266.

Al-Qabba, M. M., M. A.El-Mowafy, S. A.Althwab, H. A.Alfheeaid, T.Aljutaily and H. Barakat. 2020. Phenolic Profile, antioxidant activity, and ameliorating efficacy of chenopodium quinoa sprouts against CCl4-induced oxidative stress in rats. Nutrients. 12(10): 2904.

Ali, O. I. E.-D. 2019. Nutritional Value of Germinated Quinoa Seeds and Their Protective Effects on Rats' Health Injected by Nicotine. Egyptian J. of Food Sci. 47(2):227241.

Arfat, Y., N.Mahmood, M. U.Tahir, M.Rashid, S.Anjum. 2014. Effect of imidacloprid on hepatotoxicity and nephrotoxicity in male albino mice. Toxicology reports. 1: 554-561.
Ayyash, M., S. K. Johnson, S. Q. Liu, A.Al-Mheiri and A. Abushelaibi. 2018. Cytotoxicity, antihypertensive, antidiabetic and antioxidant activities of solid-state fermented lupin, quinoa and wheat by Bifidobacterium species: In-vitro investigations. Lwt. 95: 295-302.

Balakrishnan, G. and R. G.Schneider. 2020. Quinoa flavonoids and their bioaccessibility during in vitro gastrointestinal digestion. J. of Cereal S. 95: 103070.

Barbosa, M. L., A. A. P. M. de Meneses, R. P. S.de Aguiar, J. M. d. C.e Sousa, A. A. d. C. M.Cavalcante and S. W. Maluf. 2020. Oxidative stress, antioxidant defense and depressive disorders: A systematic review of biochemical and molecular markers. Neurology, Psychiatry and Brain Research. 36:65-72.

Batandier, C., X. Leverve and E. Fontaine. 2004. Opening of the mitochondrial permeability transition pore induces reactive oxygen species production at the level of the respiratory chain complex I. J. of Biological Chemistry. 279(17):17197-17204.

Bergman, O. and D.Ben-Shachar. 2016. Mitochondrial oxidative phosphorylation system (OXPHOS) deficits in schizophrenia: possible interactions with cellular processes. The Canadian J. of Psychiatry. 61(8):457-469.

Bhatnagar, P. and N.Jain. 1986. Morphofunctional changes in the liver of male mice after chronic treatment with phosphamidon. Bulletin of environmental contamination and toxicology. 37(1):767-773.

Black, B. C., R. M.Hollingworth, K. I.Ahammadsahib, C. D. Kukel and S.Donovan. 1994. Insecticidal action and mitochondrial uncoupling activity of AC-303,630 and related halogenated pyrroles. Pesticide Biochemistry and Physiology. 50(2):115-128.

Buege, J. and S.Aust. 1978. Microsomal lipid peroxidation Methods Enzymol. 52: 302-310. Find this article online.

Buettner, G. R. 2011. Superoxide dismutase in redox biology: the roles of superoxide and hydrogen peroxide. AntiCancer Agents in Medicinal Chemistry (Formerly Current Medicinal Chemistry-Anti-Cancer Agents). 11(4):341-346.

Caldiroli, A., A. M.Auxilia, E.Capuzzi, M. Clerici and M.Buoli. 2020. Malondialdehyde and bipolar disorder: A short comprehensive review of available literature. J. of Affective Disorders. 274:31-37.

Castresana, J., M.Lübben, M.Saraste and D. G.Higgins. 1994. Evolution of cytochrome oxidase, an enzyme older than atmospheric oxygen. The EMBO J., 13(11):2516-2525.

Chirinos, R., R.Pedreschi, M.Velásquez-Sánchez, A.Aguilar-Galvez and D.Campos. 2020. In vitro antioxidant and angiotensin I-converting enzyme inhibitory properties of enzymatically hydrolyzed quinoa (Chenopodium quinoa) and kiwicha (Amaranthus caudatus) proteins. Cereal Chemistry. 97(5):949-957.

CoHort Software: Tucson, A. 1998-2008. CoStat program http://www.cohortsoftware.com/costat6400Win.exe, Version 6.400 .

Costa, L. G. 2008. Toxic effects of pesticides. Casarett and Doull's toxicology: the basic Sci. of poisons. 8:883-930. 
De Castro, I. P., L. M.Martins and S. H. Y. Loh. 2011. Mitochondrial quality control and Parkinson's disease: a pathway unfolds. Molecular neurobiology. 43(2):80-86.

Delgado-Coello, B., R.Trejo and J. Mas-Oliva. 2006. Is there a specific role for the plasma membrane Ca 2+-ATPase in the hepatocyte? Molecular and cellular biochemistry. 285(1):1-15.

Delgado, E. H., E. L.Streck, J. L. Quevedo and F. Dal-Pizzol. 2006. Mitochondrial respiratory dysfunction and oxidative stress after chronic malathion exposure. Neurochemical research. 31(8):1021-1025.

Dhouib, I. B., M. M.Lasram, M.Abdeladhim, N.Gharbi, M. B.Ahmed and S. El-Fazaa. 2014. Immunosuppression and oxidative stress induced by subchronic exposure to carbosulfan in rat spleen: immunomodulatory and antioxidant role of $\mathrm{N}$-acetylcysteine. Toxicology mechanisms and methods. 24(6):417-427.

El-Gendy, K., K.Osman, E. E. El-Din and E. Ayman. 2019. Role of biomarkers in the evaluation of cadmium and ethoprophos combination in male mice. Environmental toxicology and pharmacology. 72:103267.

Ellman, G. L. 1959. Tissue sulfhydryl groups. Archives of biochemistry and biophysics. 82(1):70-77.

Gomaa, M., M.Abd Alla and M. M.Sameer. 2011. The possible protective effect of propolis (Bee glue) on cypermethrin-induced hepatotoxicity in adult albino rats. Mansoura J. of Forensic Medicine and Clinical Toxicology. 19(1):17-32.

Gómez, M. J. R., J. M.Prieto, V. C.Sobrado and P. C. Magro. 2021. Nutritional characterization of six quinoa (Chenopodium quinoa Willd) varieties cultivated in Southern Europe. J. of Food Composition and Analysis. 99:103876.

Green, D. and D. Ziegler. 1963. [58] Electron transport particles. Methods in Enzymology. 6:416-424.

Gultekin, F., N.Delibas, S. Yasar and I. Kilinc. 2001. In vivo changes in antioxidant systems and protective role of melatonin and a combination of vitamin $\mathrm{C}$ and vitamin $\mathrm{E}$ on oxidative damage in erythrocytes induced by chlorpyrifos-ethyl in rats. Archives of toxicology. 75(2):88-96.

Gunning, R., and G.Moores. 2002. Chlorfenapyr resistance in Helicoverpa armigera in Australia. Paper presented at the BCPC Conference: Pests and diseases, Vol. 1 and 2. Proceedings of an international conference held at the Brighton Hilton Metropole Hotel, Brighton, UK. 2:18-21.

Guven, C., Y.Sevgiler and E.Taskin. 2018. Pyrethroid insecticides as the mitochondrial dysfunction inducers. Mitochondrial Diseases. 293-322.

Hamed, N.A. 2021. Quinoa Mitigates Chlorfenapyr-Induced Testicular Toxicity in Rats. Alex. Sci . Exch. J. 42: 475486.

He, B., Y.Ni, Y. Jin and Z.Fu. 2020. Pesticides-induced energy metabolic disorders. Sci. of The Total Environment. 729: 139033. Hu, Y., J.Zhang, L.Zou, C.Fu, P. Li and G. Zhao. 2017. Chemical characterization, antioxidant, immune-regulating and anticancer activities of a novel bioactive polysaccharide from Chenopodium quinoa seeds. International J. of biological macromolecules. 99: 622-629.

Ishii, T., K.Yasuda, A.Akatsuka, O. Hino, P. S.Hartman and N. Ishii. 2005. A mutation in the SDHC gene of complex II increases oxidative stress, resulting in apoptosis and tumorigenesis. Cancer research. 65(1):203-209.

Kadota, T., Y.Okuno, H.Kohda and J. Miyamoto.1976. Mammalian Toxicological Study of Permethrin, 3phenoxybenzyl ( \pm )-cis, trans-2, 2-dimethyl-3-(2, 2dichlorovinyl)-cyclopropane-1-carboxylate. Botyukgoku. 41(4):143-151.

Karami-Mohajeri, S. and M.Abdollahi. 2013. Mitochondrial dysfunction and organophosphorus compounds. Toxicology and applied pharmacology. 270(1):39-44.

Kashimura, M. 2020. The human spleen as the center of the blood defense system. International J. of Hematology. 112(2):147-158.

King, A., M.Selak and E. Gottlieb. 2006. Succinate dehydrogenase and fumarate hydratase: linking mitochondrial dysfunction and cancer. Oncogene. 25(34): 4675-4682.

King, T. E. 1967. [58] Preparation of succinate dehydrogenase and reconstitution of succinate oxidase. In Methods in Enzymology. 10:322-331.: Elsevier.

Krause, F., N. H.Reifschneider, S.Goto and N. A.Dencher. 2005. Active oligomeric ATP synthases in mammalian mitochondria. Biochemical and biophysical research communications. 329(2):583-590.

Laothong, U. 2016. Pesticides and Non-alcoholic Fatty Liver Disease. Thai J. of Toxicology. 31(2):97-107.

Lee, H., E.Ko, S.Shin, M.Choi and K.T.Kim. 2021. Differential mitochondrial dysregulation by exposure to individual organochlorine pesticides (OCPs) and their mixture in zebrafish embryos. Environmental Pollution. 277:115904.

Lesnefsky, E., T.I.Gudz, C.T. Migita, M. Ikeda-Saito, M.O. Hassan, P.J. Turkaly and C.L. Hoppel. 2001. Ischemic injury to mitochondrial electron transport in the aging heart: damage to the iron-sulfur protein subunit of electron transport complex III. Arch Biochem Biophys. 385: 117-128.

Lim, T. K., X. Q.Shi, J. M. Johnson, M. B. Rone and J. P.Antel. 2015. Peripheral nerve injury induces persistent vascular dysfunction and endoneurial hypoxia, contributing to the genesis of neuropathic pain. J. of Neuroscience. 35(8):3346-3359.

Lowry, O. H., N. J.Rosebrough, A. L. Farr and R. J. Randall. 1951. Protein measurement with the Folin phenol reagent. J. of Biological Chemistry. 193: 265-275.

Margolis, A. M., H.Heverling, P. A.Pham and A.Stolbach. 2014. A review of the toxicity of HIV medications. J. of Medical Toxicology. 10(1):26-39.

Marí, M., A.Morales, A.Colell, C. García-Ruiz, N. Kaplowitz and J. C.Fernández-Checa. 2013. Mitochondrial glutathione: features, regulation and role in disease. Biochimica et Biophysica Acta (BBA)-General Subjects. 1830(5):3317-3328. 
Martín, M., M.Macías, G.Escames, J. León and D.AcuñaCastroviejo. 2000. Melatonin but not vitamins C and E maintains glutathione homeostasis in t-butyl hydroperoxide-induced mitochondrial oxidative stress. The FASEB J. 14(12):1677-1679.

Masoud, A., R. Kiran and R.Sandhir. 2009. Impaired mitochondrial functions in organophosphate induced delayed neuropathy in rats. Cellular and molecular neurobiology. 29(8):1245-1255.

Massart, J., K.Begriche, N.Buron, M.Porceddu, A.BorgneSanchez and B.Fromenty. 2013. Drug-induced inhibition of mitochondrial fatty acid oxidation and steatosis. Current Pathobiology Reports. 1(3):147-157.

Mohamed, D. A., K. A.Fouda and R. S.Mohamed. 2019. In vitro Anticancer Activity of Quinoa and Safflower Seeds and Their Preventive Effects on Non-alcoholic Fatty Liver. Pakistan J. of biological Sci.: PJBS. 22(8):383-392.

Mufari, J. R., A. C.Rodríguez-Ruiz, A. E.Bergesse, P. P.Miranda-Villa, V.Nepote and A. R. Velez. 2021. Bioactive compounds extraction from malted quinoa using water-ethanol mixtures under subcritical conditions. Lwt. 138:110574.

Mühleip, A., S. E.McComas and A.Amunts. 2019. Structure of a mitochondrial ATP synthase with bound native cardiolipin. Elife. 8: e51179.

N'guessan, R., P. Boko, A.Odjo, M. Akogbeto, A.Yates and M.Rowland. 2007. Chlorfenapyr: a pyrrole insecticide for the control of pyrethroid or DDT resistant Anopheles gambiae (Diptera: Culicidae) mosquitoes. Acta tropica. 102(1):69-78.

Negre-Salvayre, A., N.Auge, V. Ayala, H. Basaga and J.Boada. 2010. Pathological aspects of lipid peroxidation. Free radical research. 44(10): 1125-1171.

Oppedisano, F., R.Macrì, M.Gliozzi, V.Musolino and C.Carresi. 2020. The anti-inflammatory and antioxidant properties of n-3 PUFAs: Their role in cardiovascular protection. Biomedicines. 8(9):306.

Organization for Economic Cooperation and Development(OECD 2001); Guidelines for the testing of chemicals/draft updated test guideline; Acute Oral Toxicity Study in Rodents: 420.

Raina, R., P. K.Verma, N.Pankaj and S.Prawez. 2009. Induction of oxidative stress and lipid peroxidation in rats chronically exposed to cypermethrin through dermal application. J. of veterinary Sci. 10(3): 257-259.

Ranjbar, A., M. H.Ghahremani, M.Sharifzadeh, A.Golestani and M.Ghazi-Khansari. 2010. Protection by pentoxifylline of malathion-induced toxic stress and mitochondrial damage in rat brain. Human and experimental toxicology. 29(10):851-864.

Robinson, K. M. and J. D.Yarbrough. 1978. Liver response to oral administration of mirex in rats. Pesticide Biochemistry and Physiology. 8(1):65-72.

Samarghandian, S., M.Azimi-Nezhad, M. M.Shabestari, F. J.Azad, T.Farkhondeh and F. Bafandeh. 2015. Effect of chronic exposure to cadmium on serum lipid, lipoprotein and oxidative stress indices in male rats. Interdisciplinary toxicology. 8(3):151.
Samarghandian, S., M.Azimi-Nezhad, A.Borji and T.Farkhondeh. 2016. Effect of crocin on aged rat kidney through inhibition of oxidative stress and proinflammatory state. Phytotherapy research. 30(8):1345-1353.

Şener, G., Ö.Şehirli, Ş.Çetinel, F.Ercan, M.Yüksel. 2005. Amelioration of sepsis-induced hepatic and ileal injury in rats by the leukotriene receptor blocker montelukast. Prostaglandins, leukotrienes and essential fatty acids. 73(6):453-462.

Sharma, P., S. Firdous and R. Singh. 2014. Neurotoxic effect of cypermethrin and protective role of resveratrol in Wistar rats. International J. of Nutrition, Pharmacology, Neurological Diseases. 4(2):104.

Slane, B. G., N.Aykin-Burns, B. J.Smith, A. L.Kalen and P. C.Goswami. 2006. Mutation of succinate dehydrogenase subunit $\mathrm{C}$ results in increased $\mathrm{O} 2 \cdot-$, oxidative stress, and genomic instability. Cancer research. 66(15):7615-7620.

Sleem, F., M. M.Elalfy, A. A.Abd Allah, M. F. Hamed and M. Abomosallam. 2019. Developmental and ultrastructure toxicity of greenhouse insecticide chlorfenapyr in rat fetuses. American-Eurasian J. of Toxicological Sci. 11(1):1-10.

Taussky, H. H. and E. Shorr. 1953. A microcolorimetric method for the determination of inorganic phosphorus. $J$. of Biological Chemistry. 202(2):675-685.

Teng, C., Z.Shi, Y. Yao and G.Ren. 2020. Structural Characterization of Quinoa Polysaccharide and Its Inhibitory Effects on 3T3-L1 Adipocyte Differentiation. Foods. 9(10):1511.

Thowfeik, F. S. 2016. Targeting a common enemy: Toxic cellular mechanism of novel anti-cancer agents that alter DNA and transcription. University of Cincinnati.

Tomlin, C. 2000. The pesticide manual: a world compendium. 12th Edit. Pesticide Manual. British Corp. protection P. 14:502-504.

Tukhtaev, K., S.Tulemetov, N. Zokirova, N. Tukhtaev, M.Tillabaev. 2013. Prolonged exposure of low doses of fipronil causes oxidative stress in pregnant rats and their offspring. Internet J. of Toxicology. 10(1).

Van Leeuwen, T., V.Stillatus and L.Tirry. 2004. Genetic analysis and cross-resistance spectrum of a laboratoryselected chlorfenapyr resistant strain of two-spotted spider mite (Acari: Tetranychidae). Experimental and applied acarology. 32(4):249-261.

Wani, W. Y., S.Gudup, A.Sunkaria, A.Bal and P. P.Singh. 2011. Protective efficacy of mitochondrial targeted antioxidant MitoQ against dichlorvos induced oxidative stress and cell death in rat brain. Neuropharmacology .8(61):1193-1201.

Weil, C. S. 1952. Tables for convenient calculation of medianeffective dose (LD 50 or ED 50) and instructions in their use. Biometrics. 8(3): 249-263.

Xu, M.Y., P.Wang, Y. J.Sun, L.Yang and Y. J.Wu. 2017. Joint toxicity of chlorpyrifos and cadmium on the oxidative stress and mitochondrial damage in neuronal cells. Food and Chemical Toxicology. 103:246-252. 
Yaman, S. O. and A. Ayhanci. 2021. Lipid Peroxidation. In Lipid Peroxidation: IntechOpen.

Yao, Y., X.Yang, Z.Shi and G. Ren. 2014. Anti-inflammatory activity of saponins from quinoa (Chenopodium quinoa Willd.) seeds in lipopolysaccharide-stimulated RAW
264.7 macrophages cells. J. of Food Sci. 79(5):H1018H1023.

Zanoli, J. C. C., M. A. Maioli, H. C.Medeiros and F. E.Mingatto. 2012. Abamectin affects the bioenergetics of liver mitochondria: A potential mechanism of hepatotoxicity. Toxicology In Vitro. 26(1):51-56.

\section{الملخص العربي \\ كلورفينابير يحث خلل الفسفرة التأكسدية في الجرذان المعرضة والدورلفعال للكينوا}

$$
\text { رضا خميس عبد الرازق ونادية على حامد }
$$

أوكسيدوريدكتاز (المعقد الثالث)، السيتوكروم سى أوكسيداز

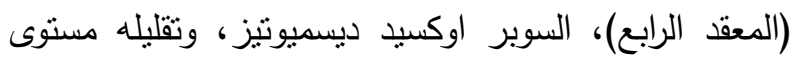
الجلوناثيون المختزل (GSH)، بالإضافة إلى زيادة كبيرة في الإنيات مستويات الأدينوزين ثلاثى الفوسفاتيز الخامس) ومستوى اكسدة الدهون في كل من ميتوكوندريا الكبد والطحال، مما يشير إلى وجود أكسدة شديد داخل

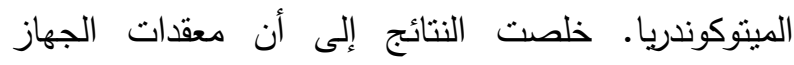

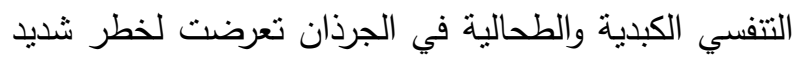
بعد المعاملة بالمبيد. علاوة على ذلك فقد لوحظ أن النظام



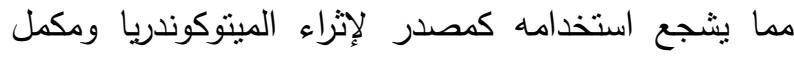
غذائي مضاد للأكسدة.

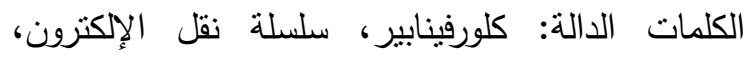

$$
\text { الميتوكوندريا، الإجهاد التأكسدي، الكينوا }
$$

تبحث هذه الدراسة في تأثيرات مركب الكلورفينابير (CFp) حث المركب لعملية الأكسدة لمعقدات الميتوكوندريا التتفسية

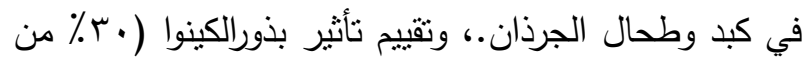

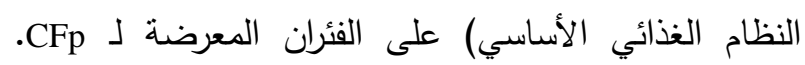
أعطيت الجرذان جرعات تحت مميتة من CFp عن طريق الأن الفم (180 مجم / كجم من وزن الجسم والتى تمنل ثلث الجرعة المسبية لموت نصف عدد الأفراد المعاملة). عزلت

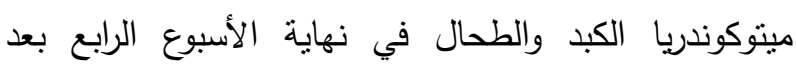
المعاملة، ثم فحصت التغيرات في معقدات تتفس ميتوكوندريا الكبد والطحال ، وما يصاحب ذلك من متغيرات فى مؤشرات

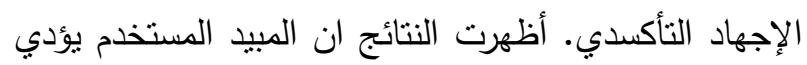

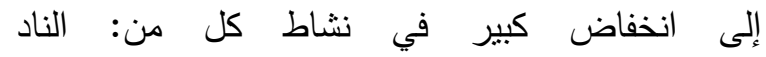
ديهيدروجينيز NADH (المعقد الأول)، السكسينات ديهيدروجينيز (المعقد الثانى)، و يوبيكوينون سيتوكروم سى التى لينيز 